\section{USE OF SCREENCAST IN DISTANCE EDUCATION GIS LESSONS: STUDENTS' VIEWS}

\begin{abstract}
This study aims to analyze the views of geography teacher students on the GIS course conducted with screencasts during the distance education process. Furthermore, the study reveals, along with the reasons, how the process of capturing and sharing screencasts with students can assist instructors. At the end of the term, 27 students studying in the second year of the geography teaching undergraduate program were asked about their opinions of the lesson. The data were collected through a structured evaluation form consisting of open-ended questions to evaluate the course. In the analysis of the comments obtained, MAXQDA software, which is frequently used in qualitative data analysis, was applied. The expressions in the answers were analyzed using the content analysis technique. Overall, the results prove that the beneficial aspects of the GIS course, which consists of applications and is conducted with screencast, outweigh the theory. Thanks to the screencast model, students can use their time efficiently and watch the videos repeatedly whenever and wherever they want. Nevertheless, the results reveal that extra methods are required to motivate students to transfer theoretical information and that screencasts have some disadvantages.
\end{abstract}

\section{KEYWORDS}

Distance education, GIS teaching, screencasts, user research

\section{HOW TO CITE}

Yıldırım S. (2021) 'Use of Screencast in Distance Education GIS Lessons: Students' Views', Journal on Efficiency and Responsibility in Education and Science, vol. 14, no. 4, pp. 247257. http://dx.doi.org/10.7160/eriesj.2021.140404

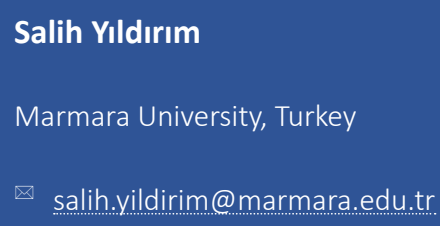

salin.yidirim@marmara.edu.tr

Article history

Received

May 30, 2021

Received in revised form

July 26, 2021

Accepted

October 27, 2021

Available on-line

December 20, 2021

\title{
Highlights
}

- Each student's ability to work according to their own learning pace or readiness is a critical advantage.

- Via screencasts, students can use their time efficiently and watch the videos repeatedly whenever and wherever they want.

- It is necessary to stay away from presentations containing only information, increase the visuals and keep the video short.

- The most crucial disadvantage is that students continue the learning process independently of the educator and their friends.

\section{INTRODUCTION AND LITERATURE}

The outbreak of the COVID-19 pandemic in various countries at the end of 2019 has transferred traditional faceto-face learning to distance education platforms (Burgess and Sievertsen, 2020; Chen et al., 2020). Social distancing rule and school closing bring about change and reform in the education system of many countries (Bao, 2020). During the COVID-19 distance education process, screencasts are one of the favorite tools preferred in lessons. Furthermore, information and communication technologies (ICT) development encourages universities to experience alternative models such as online or distance education (Albăstroiu, Felea and Vasiliu, 2014; Kauppi et al., 2020). ICT plays a vital role in both the teacher's teaching process and the student's learning process. Teachers benefit from modern technologies in teaching the lesson and students in learning the lesson (Mitchell et al., 2018; Paraskeva, Bouta and Papagianni, 2008). Although certain problems arise in the process of adapting to modern technologies, university students adapt quickly to change (Tartavulea et al., 2020). Distance education offers students important opportunities to overcome space-time limitations, provide learning time flexibility and emphasize different learning styles (Onete et al., 2014).

In recent years, many instructors have been using screencasts in their lessons (Gormely and McDermott, 2011; Luongo, 2015). While screencast is an integral part of today's education system, it also plays a vital role in higher education. For instance, Stanford and Berkeley universities use screencasts 
as an educational tool. Instructors may include screencast in distance learning, sometimes in all of their lessons, and sometimes as part of their blended learning (Brame, 2016). However, screencast software continues to become an essential part of our daily life. Although it has widespread use in many fields, videos created by screencast are frequently used, mainly in learning different computer-based software. Screencasts created and broadcast by other users have an essential place in solving the problems encountered during the use of various software.

Screencasts can also appear in the literature with the concepts of screencast and screen capture. Screencast means recording a computer screen simultaneously with sound, mouse movements, and clicks (Kawaf, 2019; Winterbottom, 2007; Snyder, Paska and Besozzi, 2014). Individuals with computer skills can use screencast software without any difficulty. In fact, the software can be downloaded for free, and its application requires very little technical knowledge (Oud, 2009; Ruffini, 2021). The screencast software was expensive in the early years of computers. On the other hand, it can be used free of charge with the development of open-source software in recent years. CamStudio and OBS (Open Broadcaster Software) studio are among the most used open-source software (Catalano, 2014). Numerous studies in the literature prove that using a screencast in lessons has many advantages for teachers and students, regardless of whether they are inside/outside the classroom (Gormely and McDermott, 2011; Luongo, 2015; Peterson, 2007; Gambari and Hassan, 2017; Hasanudin and Fitrianingsih, 2018). While (Gormely and McDermott, 2011) found screencasts useful and exciting in an online education environment, (Peterson, 2007) emphasized that using screencasts can be effective while learning software. Because while learning the software, it is of great importance where the mouse is clicked and how the screen displays simultaneously. Luongo (2015) states that she received positive feedback from students in the classroom where he used screencasts in a faceto-face education environment. In addition, in her study, she mentions that instructors outside the classroom can apply this technique.

Instructors can use screencasts in software teaching, computerbased analysis, asynchronous communication with students, PowerPoint presentations, and solving extensive problems (Lloyd and Robertson, 2012). Students, on the other hand, have the opportunity to watch their weekly programs at any time they are suitable by stopping the recordings over and over again. It may be even more beneficial for students who have learning difficulties in lessons (Roache, 2006). This type of technology enables students to move at their own pace since they can pause the classes whenever and wherever they want, go back or watch as much as they need. It also converts screencasts into a digital format that guarantees the preservation of an instructor's live lecture (Kong, 2011). The effectiveness of screencast $\mathrm{s}$ in the classroom is directly related to the qualifications of the instructors (Harrison, 2020) and the creation of high-quality recordings. To create pedagogically qualified screencast recordings: (1) all of the theory, application, and comprehension activities should be included in the curriculum of the course; the instructor of the lesson should prepare (2) all-screencast s; (3) records must be relatively short; (4) instructors should speak clearly and comprehensively; (5) records should be checked repeatedly until they reach the desired quality (Brame, 2016; Ghilay and Ghilay, 2015; Rudow and Sounny-Slitine, 2015).

Screencasts are primarily used in lessons that require software applications such as GIS training. If I had taken the GIS course as a screencast throughout my undergraduate education, it would have been easier for me to learn the course. Because reaching the instructor's speed in conducting such a course plays a vital role in following effectively. Sometimes even missing a click of the instructor's mouse can make the lesson challenging to follow. Furthermore, as an instructor who has been taking the GIS course for years, I have often observed that students record the course with smartphones in addition to taking notes. Since the GIS discipline is closely related to technological developments, the teaching and learning models of the discipline are revised depending on these advancements, and it is known that GIS instructors are in search of new in the process (Argles, 2017; Bearman et al., 2016; Harvey and Kotting, 2011; Ooms et al., 2015; Mitchell et al., 2018). GIS education involves a delicate balance between theory and applications (Ooms et al., 2015). Higher education students are required to acquire theoretical knowledge and practice on GISrelated issues. However, it should be emphasized that practice is stressed for a more extended period compared to theory. It is essential to agree on a training platform where both would be ideal. For instance, it is easier to transfer the theory to students in face-to-face education compared to GIS education with screencast. Yet, screencasts also have significant advantages in terms of running applications. According to the advantages of screencasts, the background of the study is based on the view that GIS lessons, most of which are computer-based, can be conducted with screencasts.

Many researchers have focused on the use of screencasts in lessons for educational purposes. Some of them have highlighted screencasts can be used in computer-assisted lessons (Brame, 2016; Ghilay and Ghilay, 2015; Morris and Chikwa, 2014; Smith and Smith, 2012; Winterbottom, 2007). Since GIS applications are computer-aided, screencasts can be used in GIS lessons. Some studies describe GIS education as a discipline with a high potential to be developed by educators (Argles, 2017; Ooms et al., 2015; Vojteková et al., 2021; Zerger et al., 2002). After the outbreak of the pandemic in Turkey, but also worldwide, the form of education has changed. The education form has moved to the distance form of it, implemented by e-learning. Vojteková et al., (2021), pointed out the new method of distance GIS learning during the COVID-19 pandemic. According to above-mentioned research studies, it is good idea to develop alternative methods for the applied courses such as GIS education in the distance education period. For example, Vojteková et al., (2021), prepared videos for the GIS course with the JitsiMeet application. A similar alternative as in the example is also offered by this study. For this reason, the study aims to evaluate students' views by teaching GIS through screencasts and determining the most appropriate distance education format. Specifically, it is aimed to reveal the positive and negative points of the lesson and 
suggestions for the future GIS lessons by referring opinions of the students.

In the method section, the process of how the GIS lesson is conducted, how the screencasts are shared with the students, and how the data obtained from the interview is analyzed. In the results section, the qualitative data analysis is presented to the readers. The most important findings identified in this section are compared with previous researches in the discussion section. The conclusion section briefly summarizes the most important results identified and analyses the questions of the study. In addition, the discussion and conclusion sections offer some suggestions for GIS education and provide clues for further research.

\section{MATERIALS AND METHODS}

\section{Technical Implementation: Screencasts Based GIS Instruction}

This study was conducted with bachelor's degree sophomores of the geography-teaching department at Atatürk Education Faculty of Marmara University. During the GIS lesson, the videos created with screencast were shared with the students every week, and it was aimed for the students to learn the GIS theory and applications with the open-source QGIS software. Depending on the subject content, the duration of the screencasts varies between 3 and 20 minutes. While shorter screencasts are based on theoretical issues, longer screencasts are based on applications and reinforcement activities. The application and activities demonstrate how the instructor navigates the QGIS interface gradually. The author created high-resolution screencasts with the open-source OBS (Open Broadcaster Software) Studio software. There were 27 students enrolled in this class. The GIS course lasted 14 weeks, and all documents were shared with students via Google Classroom as a ZIP file. This platform served as a center for all educational activities of the course. Course documents cover PDF files of PowerPoint slides, all data, and videos used in education. For the lesson to be more efficient, videos related to theory and applications were created separately. After the theory and practice, comprehension and gaining momentum were included. This plays a vital role in reinforcing and summarizing the subject. The most critical goal in the recording process of videos is to make minimum editing after recording. Consequently, if any problems were encountered while checking the recordings, the videos were probably retaken.

The open-ended questions created to evaluate the course were directed to the students through the structured form. With this form, the opinions of geography teacher students regarding the GIS course were determined. The validity of the form was provided by submitting it to review by other field expert. In the end, questions were added to the evaluation form prepared by the researcher with the suggestions of the other field experts. A pilot study was conducted with two students to test the form's understandability before sending it to the students. The form was finalized in line with expert suggestions and students' opinions. Twenty-seven students participating in the assessment were coded as S1, S2,...S27 (Table 1). The researcher obtained the course data regarding the classes conducted in the fall semester of the 2020-2021 academic year via e-mail. It took approximately 15-20 minutes for the form to be answered by the students. Many students wrote more than one answer to the open-ended questions in the form. Questions directed to students are as follows:

1. What are your thoughts on the process of conducting the GIS course with a screencast?

2. What problems did you encounter during the process of conducting the GIS course with screencast?

3. What are your thoughts on the process of running the GIS course with the QGIS software?

4. Would you prefer this course to be conducted in faceto-face training, screencast, or hybrid? Explain with reasons.

5. What are your suggestions regarding the content and implementation of this course in the following years?

\begin{tabular}{|c|c|c|c|c|c|}
\hline Code & Gender & Data Collection Date & Code & Gender & Data Collection Date \\
\hline S1 & $M$ & 02.17 .2021 & S15 & $\mathrm{F}$ & 02.20 .2021 \\
\hline S2 & $\mathrm{M}$ & 02.13 .2021 & S16 & $M$ & 02.19 .2021 \\
\hline S3 & $\mathrm{F}$ & 02.18 .2021 & S17 & $\mathrm{F}$ & 02.17 .2021 \\
\hline S4 & $M$ & 02.18 .2021 & S18 & $M$ & 02.17 .2021 \\
\hline S5 & $\mathrm{F}$ & 02.22 .2021 & S19 & $\mathrm{M}$ & 02.22 .2021 \\
\hline S6 & $M$ & 02.18 .2021 & S20 & $M$ & 02.19 .2021 \\
\hline S7 & $\mathrm{F}$ & 02.16 .2021 & S21 & $\mathrm{F}$ & 02.13 .2021 \\
\hline S8 & $\mathrm{M}$ & 02.16 .2021 & S22 & $M$ & 02.18 .2021 \\
\hline S9 & $\mathrm{M}$ & 02.16 .2021 & S23 & $M$ & 02.19 .2021 \\
\hline $\mathrm{S} 10$ & $\mathrm{~F}$ & 02.14 .2021 & S24 & $\mathrm{F}$ & 02.16 .2021 \\
\hline S11 & $\mathrm{M}$ & 02.19 .2021 & S25 & $M$ & 02.18 .2021 \\
\hline S12 & $\mathrm{F}$ & 02.22 .2021 & S26 & $M$ & 02.14 .2021 \\
\hline S13 & $\mathrm{M}$ & 02.13 .2021 & S27 & $\mathrm{F}$ & 02.19 .2021 \\
\hline S14 & $M$ & 02.16 .2021 & & & \\
\hline
\end{tabular}

Table 1: Characteristics of the students interviewed

As seen in table 1, 17 of the courses in which 27 students are enrolled are men, and 10 are women. The data were collected between 13.02.2021 and 22.02.2021. All of the participants are

18-23 who study at the department of geography teaching at the state university.

Content analysis technique was applied in analyzing the 
data obtained from students' expressions. The purpose of content analysis is to bring together similar expressions within the framework of specific themes and interpret them in depth (Patton, 2014; Yıldırım, A. and Şimşek, H., 2016). The first step in performing content analysis is the coding of data. Coding was done using MAXQDA, a widely-used qualitative data analysis software. First, data was collected with a Microsoft Word document, and answers were deciphered with MAXQDA software. In the deciphering process, the coding type called "coding within a general frame" was preferred. The three steps applied in terms of coding type are as follows: (i) detailed (explicit) coding was made, (ii) subcodes that mean the same with axis coding were brought together and integrated into themes, (iii) one or more statements of the students were directly quoted and given in quotation marks and interpreted.

After the data collection process, themes, categories, and codes were formed reading at least three times. The reliability rate was found according to the percentage agreement method of Miles and Huberman (1984). The reliability rate $(82 \%)$ was calculated by dividing the number of agreements by the total number of agreements plus disagreements. The three steps applied to ensure the validity of the obtained data are as follows: (i) Interview data were repeatedly reviewed, (ii) participant expressions were discussed with a different researcher, (iii) a coding table was created. Simultaneously, in order not to be limited to the researcher's interpretation, the two researchers independently developed coding categories, and the results were compared. At this stage, a code table has been prepared for coding. While creating this table, sample code table was taken as a reference (Creswell, 2015). Consequently, coding was done only if the participants' statements were related to the definition in the code table. Table 2 illustrates the codes used in this study. videos. Conducting the lesson shortly and concisely Efficient Use of Time without encountering any problems does not distract our attention. It enables us to see the activities performed in the lesson in a more holistic way." (S10)

"Thanks to the lecture being given in the form of Advantages videos, I can understand an operation that I do not get by watching it over and over again." (S27)

\begin{tabular}{|c|c|c|c|}
\hline & & & \multirow[b]{2}{*}{$\begin{array}{l}\text { "Thanks to the screencasts, we can watch the lesson } \\
\text { anytime and anywhere; this is a great benefit." (S23) }\end{array}$} \\
\hline & $\begin{array}{l}\text { The Elimination of the } \\
\text { Boundary of Time and } \\
\text { Space }\end{array}$ & 14 & \\
\hline & $\begin{array}{l}\text { Adjusting the Video } \\
\text { Speed }\end{array}$ & 6 & $\begin{array}{l}\text { "The fact that it is in the form of a video allows } \\
\text { the student to watch the video in a shorter time by } \\
\text { accelerating it according to his/her ability." (S2) }\end{array}$ \\
\hline \multirow{4}{*}{ Disadvantages } & $\begin{array}{l}\text { Students Failing to Ask } \\
\text { Interactive Questions }\end{array}$ & 13 & $\begin{array}{l}\text { "I see it as a negative situation that I cannot ask } \\
\text { the points I don't understand to the teacher and my } \\
\text { friends." (S6) }\end{array}$ \\
\hline & $\begin{array}{l}\text { Computer and Internet } \\
\text { Related Problems }\end{array}$ & 8 & $\begin{array}{l}\text { "I can say that I lagged behind the narration in the } \\
\text { video while loading the data into the program because } \\
\text { the hardware of my computer was insufficient." (S25) }\end{array}$ \\
\hline & Too Much Lesson Time & 4 & $\begin{array}{l}\text { "The longer the lesson is in person, the better it is } \\
\text { for us, but because we remain passive in front of the } \\
\text { screen in online education, it sometimes becomes } \\
\text { a problem to focus on videos for a very long time." } \\
\text { (S24) }\end{array}$ \\
\hline & $\begin{array}{l}\text { The Impermanence of } \\
\text { What is Taught }\end{array}$ & 3 & $\begin{array}{l}\text { "The videos in distance education become more, look } \\
\text { then forget' version and we have to look constantly." } \\
\text { (S9) }\end{array}$ \\
\hline
\end{tabular}

Table 2: Examples of advantages and disadvantages of screencasts theme

\section{RESULTS}

The positive and negative aspects of the GIS course, which was conducted with a screencast throughout the semester, were considered from many angles. Based on the analyzes performed in line with the data obtained, the study findings were categorized under three broad themes: (i) the advantages/disadvantages of the screencast, (ii) the conduct of the lesson, and (iii) suggestions for future lessons.

\section{Advantages of Screencast}

The beneficial aspects of conducting the GIS course with screencast are the efficient use of time and watching the videos again. The time and space limits are eliminated, and the video speed can be adjusted. The categories, codes, and the number of repetitions of the codes in the theme are given in Table 2. Efficient use of time was determined as the most frequently repeated advantage $(f=19)$. With a planned and straightforward education, it can be ensured that the lesson time is used effectively and the students save time. Factors such as 
the courses being limited to screencasts, the disappearance of individual differences, and the absence of students who cannot catch up with the applications cause a decrease in lesson time. In lessons conducted face-to-face, the instructor's answer to each student who needs repetition and correction can extend the duration of the lesson. In addition to the quality of the videos, the long or short period may affect the efficient use of time. Below is one of the student statements to support the relevant findings:

"There are individual differences in teaching; not every student can learn at the same level and speed. Some students learn faster; some learn slower. In face-to-face education, many students with different individual learning speeds are given an average amount of time, thus preventing equal opportunity in education. With video lesson teaching, each individual can learn at their own pace and use time effectively. It is one of the most significant advantages of video lessons." S21

Another advantage of continuing the course with a screencast is that students can watch videos again. Thus, students have the opportunity to repeat the topics they think are missing or forgotten as many times as they desire. In addition, it should be noted that the instructor cannot repeat every lesson from the beginning to the end in a face-to-face education to meet all the demands of the student. One of the participant statements to support the findings is below:

"Sharing the lesson with us on a screencast helps us to repeat the lesson continuously and provides the opportunity to open and look at a topic we have forgotten." (S9)

One of the essential advantages of the screencast is that it allows students to learn whenever and wherever they want. Students' readiness may not be at the expected level on class days, or students may not be able to keep up with the pace of the educator. As can be understood from the expressions of the participants, the fact that technology offers such an option benefits students.

"Since the videos are recorded, they are not subject to a specific time limit. Therefore, although I do not have the opportunity to watch it at that time, I can watch it more comfortably at a different time." (S15)

One of the essential features of today's video playback tools is that the video speed can be adjusted according to the request and purpose. In other words, thanks to the feature, students have the opportunity to progress at their own pace. In this way, students can pass the subjects they think are sufficient or progress more slowly in the sections they have difficulty understanding. One of the participants' statements regarding this is as follows:

"There are some parts of the lesson that we think is not so important in the form of screencasts. Thus, I find it essential that videos can be watched at the desired speed." (S10)

\section{Disadvantages of Screencast}

In addition to the advantages of conducting the GIS course with a screencast, there are also disadvantages. The disadvantages are that students cannot ask interactive questions, computer and internet related problems, the duration of the lesson being too long, and impermanence of what is taught. The categories, codes, and the number of repetitions of the codes in the theme are given in Table 2 . The most frequently repeated disadvantage $(f=13)$ was the students' inability to ask interactive questions. It is crucial that the students cannot simultaneously ask the instructor and their peers about their difficulty understanding. Being unable to ask questions and not interacting with other individuals in the classroom can be considered an obstacle to learning.

Furthermore, due to the lack of answers to the questions, the education process of the students may be interrupted. In this case, students may have to watch the screencasts repeatedly or skip without learning the subject. One of the participant statements to support the findings is below:

"In the training to be held face to face, we would learn the lesson by comparing it with many people. The lesson would be more fun. We could immediately ask the instructor about something we could not do or understand." (S8)

Another disadvantage of the course, which is conducted with screencasts, is the computer and internet related problems. The fact that the features of the computers such as working speed and screen quality are not at the desired level hinders the continuation of the course. It thus causes equal opportunity to be eliminated. However, poor internet speed can adversely affect the screencast's resolution and the efficient use of data. Mainly, the high raster data sizes can negatively affect the continuity of the course since it is closely related to both the quality of the computer components and internet speed. As can be seen from the following statement, some students do not have their computers or share their computers.

"We are three people studying university at home. I had a problem sharing the computer with my siblings. Our exams sometimes overlapped. And worse, the computer started freezing and shutting down for the last two weeks before the GIS exam." (S12)

Other disadvantages are the length of the lesson time and the lack of permanent teaching. The duration of the course hour may vary depending on the subject. Since it is not an interactive environment, some students stated that they could not focus on the lesson if duration of lesson gets longer. Again, for a similar reason, the lack of an interactive environment in the course may affect the permanence of the taught. Participant statements regarding the two disadvantages are as follows, respectively:

"It is important not to keep the lesson time longer than 1 hour. Since it is not interactive, the teacher's speech for more than 1 hour is not efficient." (S4) 
"After watching and applying the lecture video, unfortunately, I realize that the information is not permanent. Maybe this is just an individual problem, I am not sure." (S20)

\section{Conducting the Course}

The students' expressions related to the course's theme, which has a comprehensive framework, are collected under three headings: the course content, completing the course with QGIS, and whether the course will be carried out faceto-face with a screencast or a hybrid education model.

\section{Course Content}

The expressions belonging to the course content category were classified as future utilization $(f=22)$, comprehension/ acceleration activities $(f=22)$ and theory/practices $(f=15)$. Students express that they will benefit from the course in the future by recording screencasts, they will design maps based on the data shared in the course and the current data. When they become teacher, they want to teach geography lessons applying today's technological tools, and depending on this situation, the course may attract students. Student views on this are as follows:

"In the future, I can benefit from this software while designing maps with updated data and lecturing. According to the content of the subject to be covered, I can make the lesson better understood by using screencasts." (S1)

"When I become a teacher, I think of using GIS to increase the familiarity of students with the map and not to graduate without learning to prepare a map, albeit simple. I am sure students will be more interested in learning geography with today's technology. When I become a teacher, I would like to use recordings as a primary resource for remembering or rework GIS. " (S17)

The comprehension and acceleration activities prepared to summarize the subject left positive impressions on the students. As can be seen from the following expressions, comprehension and acceleration activities play an essential role in reinforcing the issue, the permanence of what has been learned, and the preparation process for the exam.
"I think that having comprehension and acceleration activities at the end of the lesson has a significant effect on our learning both in terms of reinforcement of the lesson and preparation for exams." (S9)

"Thanks to the comprehension and acceleration activities at the end of the practice lesson, which the instructor also demonstrated in the screencast, I repeated myself and ensured the permanence of what I learned and transferred the information." (S21)

Firstly, screencasts consisting of theoretical information were prepared within the course scope, and then applications were included. Theoretical information was shared with the students as a PDF document. The statements of the two students regarding the theory and practices that are complementary to each other are as follows:

"Theoretical knowledge helps me make sense of the subject in my mind. Since the theory parts are recorded in PDF format, it is more permanent than a verbal narration for me. Therefore, I can progress by reading and understanding sentences one by one. The application part includes the theoretical knowledge being made by a guide. Thus, I find the opportunity to understand the missing places in theory or that I do not entirely understand." (S14)

"The theoretical information is straightforward and understandable. When we look at it, the information we encounter in some lessons must also be related to our class. There are no topics that we can say what its benefit is. The data is directly related to the content and objectives of the course. The applications are also very instructive in a way that theoretical knowledge is supported. Variations in the implementation phase can make the lesson more enjoyable." (S23)

\section{Conducting the Course with QGIS}

QGIS software was preferred for conducting the GIS course due to its open-source code and handy interface. The students' expressions belonging to the category were collected in 2 classes as positive thoughts and problems encountered. Detailed information about the classification is in Table 3.

\begin{tabular}{|c|c|c|c|c|c|}
\hline Category & Codes & $f$ & Category & Codes & $f$ \\
\hline \multirow{7}{*}{ Positive Factors } & Downloading and Installing & 24 & \multirow{7}{*}{$\begin{array}{l}\text { Problems } \\
\text { Encountered }\end{array}$} & The Interface is Not the Same & 10 \\
\hline & Data Management & 14 & & Viewing Data & 7 \\
\hline & Ease of Use & 9 & & Software Language & 4 \\
\hline & Being Free of Charge & 6 & & Subject Based & 3 \\
\hline & Turkish Language Support & 2 & & Internet Speed & 2 \\
\hline & Appealing to Different Users & 1 & & Software Shutdown Suddenly & 1 \\
\hline & Updating & 1 & & Software Opening Duration & 1 \\
\hline
\end{tabular}

Table 3: Categories, codes and number of repetitions for conducting the course with QGIS

\section{Positive Factors}

The positive opinions of the students regarding the conduct of the course with QGIS were determined. Particularly downloading and installing the software, data management, ease of use, and being free of charge have been defined as the most significant codes. Downloading and installing the software can be done effortlessly compared to much open-source software. Mainly the students with sufficient hardware and internet speed stated that they did not encounter any problems. One of the participant statements to support the findings is below: 
"I did not encounter any problems with downloading and installing QGIS on my computer; it was effortless to install." (S16)

Another positive aspect of the course conducted with QGIS is the management of the data. Since data management has a structure that can differ from user to user, various features have been determined. These features can be listed as recording, viewing, storing, and analyzing data. Below are two of the expressions that determined the positive opinions of the participants on the related issues:

"For someone who is not very experienced in using a computer, data management and application interface, etc. may seem complicated at first, but I did not have a problem with these issues; I think it is an excellent program." (S11)

"The QGIS software did not cause any problems while storing the maps we created, adding raster or vector data to the program, and analyzing this data." (S17)

Ease of use is another positive finding obtained from teachers' expressions. More problems can be encountered, especially in the use of open-source software. Yet, as can be understood from the expressions, QGIS has an efficient, simple, and original design in the effective use of the interface while making applications or in map production. Two of the participant expressions in which positive thoughts were detected are below:

"In general, I enjoyed learning how to draw maps with this application since it has many features, and you can design products freely. When I saw other options while designing a map, noticing that this application will allow us to develop maps in almost all the ways we want, it will encourage me to try other buttons and create original products." (S2)

"I think the QGIS program makes the lesson better and easier to understand. A very useful program. I also found that as I spent time with the program, I learned new and more things." (S25)

The fact that the software is free, Turkish language support, appealing to different users, and being updated are other essential factors determined from the expressions of the participants. The fact that the software is free is a critical feature in increasing the number of users. The budget's being allocated for educational materials in our country is at a level that can be regarded as limited increases the importance of software even more. The fact that it provides Turkish language support significantly affects the use of the software by students. The software appeals to a wide range of users with its long-term and latest version options. Versions are updated in specific time frames. The students' views regarding all these positive factors are as follows:

"GIS software offers the maximum features a free software can.” (S6)
"Turkish language support made it very easy for us to use the software." (S13)

"Thanks to its different versions, QGIS is also a perfect application that can appeal to different users." (S2)

“It's nice to see the app being updated." (S6)

\section{Problems Encountered}

In addition to the advantages of using the QGIS software, the problems faced by students are also not gone. A significant portion of the students stated that they encountered difficulties differentiating the interface and displaying the data. Other problems encountered were software language, subjectbased, internet speed, sudden shutdown of the software, and opening time of the software. Today's software offers many alternatives for the user to design their interface practically and freely. Although the differentiation of the interfaces increases the practicality of the user, it makes it difficult to follow the lesson with screencasts. The fact that QGIS has many add-ons and manually adding these add-ons to the interface can negatively affect the process. In this sense, the views of a student who faced the problem are as follows:

"The program we use in this lesson may differ for every user. In particular, we had to add the tools we used in some projects manually. There were problems since we couldn't put everything we watched in the screencast into action immediately. Encountering these stages many times slows down learning." (S7)

Some of the students stated that they had problems viewing the data. Since a significant part of the data in GIS works with different extension files, such as the coordinate reference system, there is more than one extension file on the data insertion screen. Knowing which extension files will be added to the interface and selecting the correct extension file when dragging to solve the problem is essential. In addition, since the resolution of raster data is high, there may be a slowdown depending on the computer's performance and the internet. The views of a student who have encountered problems with data viewing are as follows:

"Sometimes it failed while uploading data to the computer. Because the data in the video could be loaded quickly and opened without any problems when loaded, but although I did the same as in the video, there were sometimes errors." (S8)

Although QGIS is Turkish-supported, it does not have the desired level of Turkish writing language functionality in many features such as tools, panels, plug-ins, warnings, etc. Students may also encounter subject-based problems. The difficulty level of some subjects requires higher-level skills compared to others. This situation makes it difficult to follow the course. The process of displaying high-sized raster data in the interface when adding base maps is directly proportional to the internet speed. In some unforeseen situations or primarily due to user error, QGIS may shut down suddenly. 
Eventually, depending on the features of the computer, the first opening of the software requires a long time. Examples of student statements regarding the problems mentioned in the paragraph are given in Table 4.

\begin{tabular}{l|l}
\multicolumn{1}{c}{ Codes } & \multicolumn{1}{c}{ Example } \\
$\begin{array}{l}\text { Software Language } \\
\text { "The language of the version I used was mixed English and Turkish version. Since Since I do not speak } \\
\text { English, I had a problem, but I solved it with the help of the internet." (S21) }\end{array}$ \\
$\begin{array}{ll}\text { "I had problems with join, area calculator, and spatial interrogation by condition. I solved these problems } \\
\text { by watching the class videos again." (S1) }\end{array}$ \\
\hline Internet Speed & "Some data may take a long time to display, depending on internet speed." (S5) \\
\hline Software Shutdown Suddenly & "I run over the course because the application suddenly closed while I was using it." (S12) \\
\hline Software Opening Duration & "It keeps a little longer while opening the application." (S22)
\end{tabular}

Table 4: Students' statements about other problems encountered

\section{Screencast or Face-to-Face or Hybrid?}

The question "Would you prefer to conduct the course face-toface or hybrid with a screencast" and their reasons were asked to the students. Of the 27 students, 14 preferred screencasts, seven preferred hybrid training, and six face-to-face training. The reasons behind the preferences also reveal that GIS training is more accepted with screencasts. We have mentioned the advantages and disadvantages of screencasts earlier. The benefits of screencasts are more effective in choosing this method more (Table 2). Factors such as the ability to watch the videos again, the efficient use of the lesson time, and the students' ability to choose the time and place are the factors behind the choice, as can be seen from the statements of the two students below.

"When the training is given to more than one person in face-toface education, there is a constant interruption due to the students' diverse comprehension abilities during the course, and it disrupts the lesson. Going back to unclear topics repeatedly can also lead to confusing situations. When it is processed with a screencast, everyone can learn the parts they do not understand or are missing by watching the video again easier by watching the lecture video at any time. In this respect, I think it is more appropriate to conduct the lesson via screencast." (S13)

"I would definitely prefer it to be played with screencasts. If I were taking the GIS course face to face, I would feel stress and pressure on myself, as it would be more difficult for me to follow the teacher. Sometimes it can take a long time because I do not have prior knowledge to perform the most effortless operation on the computer, and I do not gain enough practicality. In face-toface education, this situation could lead to incompatibility in the classroom. While the teacher was explaining a different process, my coming back might have slowed down the processing of the lesson. For such reasons, I prefer the GIS course to be conducted with videos. To be able to access lecture videos whenever I need them, to watch an action again, to reapply it, etc. It is advantageous for me. In this way, I can progress at my own pace and benefit from videos within the program I have determined." (S27)

Unquestionably, each model has its pros and cons. Hybrid education can make a difference because it involves the other two education models. Face-to-face teaching in Flipped Classroom is a method that is suitable for the blended learning hybrid education model. The student completes a specific part of the lesson at home and the rest in the classroom. A training model in which both face-to-face and screencast training will be applied may be ideal. Students both have the opportunity of in-class education. They can repeat the subjects they need to repeat whenever and wherever they want. The statements of the two students regarding this situation are as follows:

"I prefer this course to be hybrid. I think it would be much more effective teaching if acceleration activities are shared with students as homework or videos to watch. A more beneficial lesson will emerge with the combination of the positive aspects of video and face-to-face training. " (S6)

"We would suffer a lot of time and subject in the face-to-face training because it was a computer lesson, but we would learn the lesson by comparing it with many people. The lesson would be more fun. We could immediately ask the teacher about something we could not do or understand. When we go home after receiving the face-to-face training, we sometimes forget the topics, so I also think that the narration is necessary, thanks to the screencast, to reinforce this lesson and to help us later." (S8)

The reasons for students who prefer screencasts are directly proportional to the advantages of screencasts. The reasons for the students who prefer face-to-face education are also directly proportional to the disadvantages of screencasts. As can be seen from the student views below, the need to teach the course interactively comes to the fore.

"The GIS course is a course that needs to be progressed interactively. When the student makes any mistake, the educator's intervention in that error should be instant. Because a mistake made in the GIS course can cause the application to start over." (S4)

"It is certain that it will be better to conduct the course face to face with the instructor to find immediate solutions to more permanent and immediate problems. " (S22)

\section{Suggestions for Future Courses}

Students' opinions were sought to improve the quality of the future lessons. The codes in the theme, the number of repetitions, and examples of the codes are in Table 5. Many applications were shared with the students in practice or comprehension 
and acceleration activities depending on the subject. Despite this, students suggest increasing the practices in the following lessons. Some of the students also made suggestions to reduce the share of theory in the lesson's teaching. Since the study group consists of students, the students associate the maps with the maps used in the high school geography lesson and recommend that the course content be enriched in this respect.
With the presence of many applications, no homework was given in the course. It has been determined that if the homework is not given, the students will mostly work during the exam week, or the learned ones will not be permanent. Even though much data is shared during the course, students suggest that more diverse data should be shared. In addition to all these, a student indicates that the course should be taught by coding.

\begin{tabular}{|c|c|c|}
\hline Codes & $\begin{array}{c}\text { Number of Repetitions } \\
\text { of Codes }\end{array}$ & Example \\
\hline $\begin{array}{l}\text { Increasing } \\
\text { Applications }\end{array}$ & 11 & $\begin{array}{l}\text { "I think there should be more comprehension and acceleration activities within the course } \\
\text { than theoretical knowledge." (S5) }\end{array}$ \\
\hline $\begin{array}{l}\text { Mitigating the } \\
\text { Theory }\end{array}$ & 7 & $\begin{array}{l}\text { "The effect of the theoretical information presented in the course is less than the } \\
\text { applications. Reducing the theoretical knowledge in some subjects and giving more place to } \\
\text { the applications will make it easier for them to teach the course." (S7) }\end{array}$ \\
\hline $\begin{array}{l}\text { Subject-Based } \\
\text { Applications }\end{array}$ & 5 & $\begin{array}{l}\text { "I would like to learn more in terms of the use of GIS in the teaching of which units at grade } \\
\text { levels in the geography lesson curriculum." (S21) }\end{array}$ \\
\hline $\begin{array}{l}\text { Assigning } \\
\text { Homework }\end{array}$ & 3 & $\begin{array}{l}\text { "GIS is ultimately a programming course, and the more practice is, the better. My humble } \\
\text { advice is that I think more permanent learning can be achieved by giving weekly practical } \\
\text { assignments to students." (S17) }\end{array}$ \\
\hline More Data Sharing & 2 & $\begin{array}{l}\text { "It would be appropriate to share more data with students in a categorized way. Thus, the } \\
\text { student will be able to make different applications using that data." (S15) }\end{array}$ \\
\hline Including Coding & 1 & "I would like to learn more information based on coding in the course." (S10) \\
\hline
\end{tabular}

Table 5: Codes, number of repetitions of codes and examples

\section{DISCUSSION}

There are GIS courses in many disciplines in higher education. A significant portion of these courses is conducted face-to-face, some online, and some with hybrid education. In addition to all these, it can be mentioned that there are researchers who have tried different educational models or who are looking for a model. The computer-based applications needed in conducting GIS courses are the common point of education models. It is known that screencasts in computer-aided lessons will benefit the education process (Brame, 2016; Ghilay and Ghilay, 2015; Morris and Chikwa, 2014; Smith and Smith, 2012). It indicates that screencast can be used effectively in GIS lessons. Zerger et al. (2002) mention that GIS education is a discipline with a very high potential to be developed by practitioners and educators due to its nature. Similarly, Argles (2017) used a screencast in some of the GIS training, and the students liked the videos. Vojteková et al. (2021) shared the videos they prepared for the GIS course with the JitsiMeet application which was programmed for their university during the COVID 19 process and students found the application highly useful. According to the findings of this research, this course, which is conducted with screencasts for one semester, has advantages and limitations. Despite some limitations, 14 out of 27 students who attended the course support the continuation of the course with a screencast in the coming years with their reasons.

\section{Benefits}

First of all, it should be stated that screencast has many advantages regardless of GIS training. However, we know that the power of screencast is even more prominent in computer applications (Ghilay and Ghilay, 2015; Smith and Smith, 2012). Conducting the lesson with this model when the video editing rules are followed and used effectively in computer applications enables students to use their time efficiently and watch the videos repeatedly whenever they want, in the place and speed they want (Vojteková et al., 2021). Even these advantages alone form the background of the course being taught with this model or being accepted by more students. In addition, the elimination of individual differences, that is, each student's ability to work according to their own learning pace or readiness is another critical advantage. When GIS applications are performed face to face in classrooms, not every student can keep up with the speed of the educator. Even a single click with the mouse missed by the student can disrupt the flow, which may cause the lesson's duration to be prolonged. The negativities mentioned above are eliminated with the screencast, especially realizing applications and increasing the number of applications becomes easier. During the course, the number of applications was increased by comprehension/gaining speed activities. This situation gained the appreciation of many students. Open source QGIS software was preferred in the course. The materials used in educational environments being free of charge, especially in developing countries such as Turkey (education supports and services, in general, differ considerably compared to developed countries), indicating a significant obstacle to the widespread use of the material be eliminated. In addition, the software has many users around the world. Being a user-friendly software, organizing the interface according to the user, being free of charge and simple data management increase the attractiveness of QGIS.

As an educator, I observed that students' success and their grades in exams increased compared to face-to-face lessons. Especially the students who were not good with computers were having problems in their GIS lessons. Since the applications were not registered, they asked me to repeat the lesson many times. We could do this a limited number of times. The readiness of the course videos means that the instructor devotes more time to the 
questions from the students regarding the course, gives feedback to the students, and provides personal guidance. It is also an excellent advantage for me to be able to use the current videos in future lessons. In this process, I also observed that students could make their map designs at a higher level. Moreover, it opens the door to reach individuals who have the motivation to learn GIS through registrations and different platforms. Although it is challenging to guide them as they are not enrolled in formal education, it is positive for my motivation that the education reaches more people.

\section{Limitations, Possible Solutions and Further Research}

In addition to the benefits of the screencast, there are also many limitations to be considered. However, as long as the instructors are willing to plan the future effectively and strategically throughout the term, limitations seem to be resolved (Rudow and SounnySlitine, 2015). The most crucial disadvantage is that students continue the learning process independently of the educator and other friends. When students face a problem, they may have difficulty asking the instructor or peers questions, interrupting the learning process (Ronchetti, 2010; Vojteková et al., 2021). The differences in the software interface are the possible causes of the problems experienced in the applications. Although users can differentiate the interface according to their wishes, a standard interface can be designed for solutions at specific points. It is necessary to take precautions against problems arising from the quality of computer equipment and the internet. The doors of the existing laboratory can be kept open to students with inadequate equipment or low internet speed. Since one of the students enrolled in the course did not have a computer, he used the GIS laboratory. Another disadvantage is that the theory-based lessons are also conducted with the screencast. In this regard, students should be extra motivated by using technological tools effectively (Ooms et al., 2015). For the theory to be successful, it is necessary to stay away from presentations containing only information, increase the visuals and keep the video time short. When we consider the disadvantage for the instructor, the problems that arise in the preparation of the screencast are the main problems. In this regard, it is necessary to have specific qualified equipment such as headphones. Besides, a quiet environment should be preferred for better recording. Because the emergence of independent sounds that disrupt the flow during recording may mean that the recording is retaken or divided.

Researchers can plan their future studies by (i) taking measures against the disadvantages of the screencast, (ii) simplifying the interface of the software used in screencasts and moving from a standard design, (iii) paying attention to increasing the visuality in the presentation of theoretical information or adopting the hybrid education model in the theory part of the course, (iv) taking strict measures against the problems that may arise during the recording process.

\section{CONCLUSION}

In this study, second-year GIS lecture series were delivered via screencasts in geography teaching department. The rationale behind the survey was to teach GIS with the help of screencasting and to determine the most appropriate formats for distance education. The results show that the students welcomed the conduct of the entire GIS lecture with screencast technology. Instructor qualifications and the desire of instructors to produce technically first-class screencast play an important role in the effectiveness of video recordings. Screencasts have the flexibility to learn independently and students can use their time efficiently and watch the videos repeatedly whenever and wherever they want. However, there is no doubt that the instructor will have more difficulty preparing the lesson with the screencast. Although recording and editing videos require more time than face-to-face training, using recordings prepared in the coming years also means saving time in this process. Most importantly, the instructor can ensure that students get the maximum efficiency from the lecture. Based on my own experiences and student opinions, it is clear that the lecture is more efficient with the screencast. In addition, the instructor can deliver screencasts to a much larger number of students through different platforms.

\section{ACKNOWLEDGEMENT}

This paper grew out of the 2nd Istanbul International Geography Congress, organized by Istanbul University, Geography Department and Turkish Geographical Society on June 17-18, 2021. It was benefited enormously by comments and suggestions from the reviewers of this journal.

\section{REFERENCES}

Albăstroiu, I., Felea, M. and Vasiliu, C. (2014) 'Geographic Information System-modern teaching method in business administration', Amfiteatru Economic Journal, Vol. 16, No. 37, pp. 770-783.

Argles, T. (2017) 'Teaching practical science online using GIS: a cautionary tale of coping strategies', Journal of Geography in Higher Education, Vol. 41, No. 3, pp. 341-352. https://doi.org/1 $\underline{0.1080 / 03098265.2017 .1315531}$

Bao, W. (2020) 'COVID-19 and online teaching in higher education: A case study of Peking University', Human Behavior and Emerging Technologies, Vol. 2, No. 2, pp. 113-115. https://doi. org/10.1002/hbe2.191
Bearman, N., Jones, N., André, I., Cachinho, H. A. and DeMers, M. (2016) 'The future role of GIS education in creating critical spatial thinkers', Journal of Geography in Higher Education, Vol. 40, No. 3, pp. 394-408. https://doi.org/10.1080/03098265. $\underline{2016.1144729}$

Brame, C. J. (2016) 'Effective educational videos: Principles and guidelines for maximizing student learning from video content', CBE_Life Sciences Education, Vol. 15, No. 4, pp. 1-6. https:// doi.org/10.1187/cbe.16-03-0125

Burgess, S. and Sievertsen, H. (2020) Schools, skills, and learning: The impact of COVID-19 on education, [Online], Available at: https://voxeu.org/article/impact-covid-19-education $\left[\begin{array}{ll}21 & \mathrm{Jul}\end{array}\right.$ 2021]. 
Catalano, A. (2014) 'Improving distance education for students with special needs: A qualitative study of students' experiences with an online library research course', Journal of Library \& Information Services in Distance Learning, Vol. 8, No. 1-2, pp. 17-31. https:// doi.org/10.1080/1533290X.2014.902416

Chen, T., Peng, L., Yin, X., Rong, J., Yang, J. and Cong, G. (2020) 'Analysis of user satisfaction with online education platforms in China during the COVID-19 pandemic', Healthcare, Vol. 8, No. 3, 200. https://doi.org/10.3390/healthcare 8030200

Creswell, J. W. (2015) 30 essential skills for the qualitative researcher, Thousand Oaks, California: Sage Publications.

Gambari, A. I. and Hassan, S. A. (2017) 'Effects of instructional screencast on the performance of National Open University undergraduates in educational technology in Kwara State, Nigeria', Bulgarian Journal of Science and Education Policy, Vol. 11, No. 1, pp. 132-159.

Ghilay, Y. and Ghilay, R. (2015) 'Computer Courses in HigherEducation: Improving Learning by Screencast Technology', Journal of Educational Technology, Vol. 11, No. 4, pp. 15-26 https://doi. org/10.26634/jet.11.4.3148

Gormely, K. and McDermott, P. (2011) 'Do You Jing? How Screencasting Can Enrich Classroom Teaching and Learning', Language and Literacy Spectrum, Vol. 21, No. 1, pp. 12-20.

Harrison, T. (2020) 'How distance education students perceive the impact of teaching videos on their learning', Open Learning: The Journal of Open, Distance and e-Learning, Vol. 35, No. 3, pp. 260-276. https:// doi.org/10.1080/02680513.2019.1702518

Harvey, F. and Kotting, J. (2011) 'Teaching mapping for digital natives: New pedagogical ideas for undergraduate cartography education', Cartography and Geographic Information Science, Vol. 38, No. 3, pp. 269-277. https://doi.org/10.1559/1523040638269

Hasanudin, C. and Fitrianingsih, A. (2018) 'Flipped classroom using screencast-o-matic apps in teaching reading skill in Indonesian language', International Journal of Pedagogy and Teacher Education, Vol. 2, pp. 151-158. https://doi.org/10.20961/ijpte.v2i0.25356

Kauppi, S., Muukkonen, H., Suorsa, T. and Takala, M. (2020) 'I still miss human contact, but this is more flexible-Paradoxes in virtual learning interaction and multidisciplinary collaboration', British Journal of Educational Technology, Vol. 51, No. 4, pp. 1101-1116. https://doi.org/10.1111/bjet.12929

Kawaf, F. (2019) 'Capturing digital experience: The method of screencast videography', International Journal of Research in Marketing, Vol. 36, No. 2, pp. 169-184. https://doi.org/10.1016/j.ijresmar.2018.11.002

Kong, S. C. (2011) 'An evaluation study of the use of a cognitive tool in a one-to-one classroom for promoting classroom-based dialogic interaction', Computers \& Education, Vol. 57, No. 3, pp. 18511864. https://doi.org/10.1016/j.compedu.2011.04.008

Lloyd, S. A. and Robertson, C. L. (2012) 'Screencast tutorials enhance student learning of statistics', Teaching of Psychology, Vol. 39, No. 1, pp. 67-71. https://doi.org/10.1177/0098628311430640

Luongo, N. (2015) 'Missing the chalkboard: Using screencasting in the online classroom', Computers in the Schools, Vol. 32, No. 2, pp. 144-151. https://doi.org/10.1080/07380569.2015.1030968

Miles, M. B. and Huberman, A. M. (1984) Qualitative data analysis: A sourcebook of new methods, Beverly Hills: Sage Publications.

Mitchell, J. T., Roy, G., Fritch, S. and Wood, B. (2018) 'GIS professional development for teachers: Lessons learned from high-needs schools', Cartography and Geographic Information Science, Vol. 45, No. 4, pp. 292-304. https://doi.org/10.1080/15230406.2017.1421482

Morris, C. andChikwa, G.(2014) 'Screencasts: How effectivearetheyandhow do students engage with them?', Active Learning in Higher Education, Vol. 15, No. 1, pp. 25-37. https://doi.org/10.1177/1469787413514654
Onete, B., Pleșea, D., Teodorescu, I. and Cîrstea, A. (2014) 'Evolutions and opportunities of business education in the context of educational reform from the digital age', Amfiteatru Economic Journal, Vol. 16, No. 37, pp. 746-758.

Ooms, K., De Maeyer, P., De Wit, B., Maddens, R., Nuttens, T., Van De Weghe, N. and Vervust, S. (2015) 'Design and use of web lectures to enhance GIS teaching and learning strategies: the students' opinions', Cartography and Geographic Information Science, Vol. 42, No. 3, pp. 271-282. https://doi.org/10.1080/15230406.2015.1011236

Oud, J. (2009) 'Guidelines for effective online instruction using multimedia screencasts', Reference Services Review, Vol. 37, No. 2, pp. 164-177. https://doi.org/10.1108/00907320910957206

Paraskeva, F., Bouta, H. and Papagianni, A. (2008) 'Individual characteristics and computer self-efficacy in secondary education teachers to integrate technology in educational practice', Computers \& Education, Vol. 50, No. 3, pp. 1084-1091. https://doi.org/10.1016/j. compedu.2006.10.006

Patton, M. Q. (2014) Qualitative research \& evaluation methods: Integrating theory and practice, $4^{\text {th }}$ edition, Thousand Oaks, CA: Sage publications.

Peterson, E. (2007) 'Incorporating screencasts in online teaching', The International Review of Research in Open and Distributed Learning, Vol. 8, No. 3, pp. 1-4. https://doi.org/10.19173/irrodl.v8i3.495

Roache, J. (2006) 'Using screen capture technology to develop on-line course material', Proceedings of Society for Information Technology and Teacher Education International Conference, Chesapeake, pp. 519-520.

Ronchetti, M. (2010) 'Using video lectures to make teaching more interactive', International Journal of Emerging Technologies in Learning, Vol. 5, No. 2, pp. 45-48. https://doi.org/10.3991/ijet.v5i2.1156

Rudow, J. and Sounny-Slitine, M. A. (2015) 'The use of web-based video for instruction of GIS and other digital geographic methods', Journal of Geography, Vol. 114, No. 4, pp. 168-175. https://doi.org /10.1080/00221341.2014.977932

Ruffini, M. F. (2021) Screencasting to Engage Learning, [Online], Available at: https://er.educause.edu/articles/2012/11/screencastingto-engage-learning [2 Mar 2021].

Smith, J. G. and Smith, R. L. (2012) 'Screen-capture instructional technology: A cognitive tool for designing a blended multimedia curriculum', Journal of Educational Computing Research, Vol. 46, No. 3, pp. 207-228. http://dx.doi.org/10.2190/EC.46.3.a

Snyder, C., Paska, L. M. and Besozzi, D. (2014) 'Cast from the past: Using screencasting in the social studies classroom', The Social Studies, Vol. 105, No. 6, pp. 310-314. https://doi.org/10.1080/003 $\underline{77996.2014 .951472}$

Tartavulea, C. V., Albu, C. N.,Albu, N., Dieaconescu, R. I. and Petre, S. (2020) 'Online Teaching Practices and the Effectiveness of the Educational Process in the Wake of the COVID-19 Pandemic', Amfiteatru Economic, Vol. 22, No. 55, pp. 920-936. https://doi.org/10.24818/EA/2020/55/920

Vojteková, J., Tirpáková, A., Gonda, D., Žoncová, M. and Vojtek, M. (2021) 'GIS Distance Learning during the COVID-19 Pandemic (Students' Perception)', Sustainability, Vol. 13, No. 8, 4484. https:// doi.org/10.3390/su13084484

Winterbottom, S. (2007) 'Virtual lecturing: Delivering lectures using screencasting and podcasting technology', Planet, Vol. 18, No. 1, pp. 6-8. https://doi.org/10.11120/plan.2007.00180006

Yıldırım, A. and Şimşek, H. (2016) Sosyal bilimlerde nitel araştırma yöntemleri, Ankara: Seçkin Publication.

Zerger, A., Bishop, I. D., Escobar, F. and Hunter, G. J. (2002) 'A selflearning multimedia approach for enriching GIS education', Journal of Geography in Higher Education, Vol. 26, No. 1, pp. 67-80. https:// doi.org/10.1080/03098260120110377 